\title{
In Situ FTIR-ATR Analysis and Titration of Carboxylic Acid Terminated SAMs
}

\author{
Olga Gershevitz, Chaim N. Sukenik*
}

Chemistry Department, Bar-Ilan University, Ramat Gan 52900 ISRAEL

e-mail: sukenc@mail.biu.ac.il

RECEIVED DATE (will be automatically inserted after manuscript is accepted)

\section{Supplementary Information}

\begin{abstract}
Synthesis of Methyl 16-heptadecenoate
A flame-dried three-neck $250 \mathrm{~mL}$ flask equipped with a pressure-equalizing addition funnel, a reflux condenser with a $\mathrm{N}_{2}$ inlet, and a magnetic stirring bar, was charged with Mg turnings (4.67 g, $192 \mathrm{mmol}$ ). The addition funnel was charged with a solution of 16-bromo-1-hexadecene ${ }^{43}(5 \mathrm{~g}, 16.5 \mathrm{mmol})$ in $100 \mathrm{~mL}$ of dry THF. A portion of this solution $(30 \mathrm{~mL})$ was added to the flask and it was gently warmed to initiate the Grignard reaction. Once Grignard formation began, the rest of the solution was added over a period of $30 \mathrm{~min}$, followed by an additional $1 \mathrm{~h}$ of reflux. Grignard formation was monitored by TLC (silica gel/hexane). The solution was cooled to room temperature. To a two-neck $250 \mathrm{~mL}$ flame-dried flask, fitted with a pressureequalizing additional funnel, magnetic stirring bar, and $\mathrm{N}_{2}$ inlet, was added $50 \mathrm{~mL}$ of a solution of methyl chloroformate (4 $\mathrm{mL}, 58 \mathrm{mmol}$ ) in THF. This solution was cooled in an ice/salt bath to $-10{ }^{\circ} \mathrm{C}$. The Grignard reagent from the first flask was transferred to the addition funnel by syringe. It was then added dropwise to the flask. A solution of $\mathrm{LiCl}(70 \mathrm{mg}) \mathrm{and} \mathrm{CuCl}_{2}$ $(200 \mathrm{mg})$ in THF $(15 \mathrm{~mL})$ was then added to the reaction flask. The resulting mixture was stirred at $-10{ }^{\circ} \mathrm{C}$ for $8 \mathrm{~h}$. The flask was warmed to room temperature and diethyl ether $(50 \mathrm{~mL})$ was added and the entire contents were transferred to a separatory funnel. The organic solution was washed twice with saturated aqueous $\mathrm{NH}_{4} \mathrm{Cl}$ and once with saturated aqueous $\mathrm{NaCl}$, dried over anhydrous $\mathrm{MgSO}_{4}$, and concentrated on a rotary evaporator. The crude product was purified by flash chromatography (silica gel / hexane:ethyl acetate, 90:10). The yield was $2.48 \mathrm{~g}(52 \%)$. The material obtained was identical to that reported ${ }^{44}$. ${ }^{1}$ H-NMR $\delta(\mathrm{ppm}): 3.8(\mathrm{~s}, 3 \mathrm{H}), 2.3(\mathrm{t}, J=8,2 \mathrm{H}), 5.8(\mathrm{~m}, 1 \mathrm{H}), 4.7(\mathrm{~m}, 2 \mathrm{H}), 1.9-2.1(\mathrm{~m}, 2 \mathrm{H}), 1.6-1.8(\mathrm{~m}, 2 \mathrm{H}), 1.2-1.5(\mathrm{~m}, 22 \mathrm{H})$. ${ }^{13}$ C NMR $\delta$ (ppm): 173.9, 138.94, 114.48, 51.53, 34.39, 33.87, 29.60 (2C), 29.31, 29.19 (2C), 28.98 (2C), 28.80 (2C), 28.73 (2C), 25.13. MS: $\mathrm{C}_{18} \mathrm{H}_{34} \mathrm{O}_{2} ; 282.182$ (found), 282.17 (calculated).
\end{abstract}

\section{Synthesis of Methyl 17-(trichlorosilyl)heptadecanoate}

Into a $20 \mathrm{~mL}$ pressure tube containing a magnetic stirring bar was placed methyl 16-heptadecenoate $(2.28 \mathrm{~g}, 8.08 \mathrm{mmol}), \mathrm{HSiCl}_{3}$ (7 mL), and $10-20 \mu \mathrm{L}$ of a $4 \%$ solution of $\mathrm{H}_{2} \mathrm{PtCl}_{6} \bullet 6 \mathrm{H}_{2} \mathrm{O}$ in $i$-PrOH. All transfers were done under a nitrogen atmosphere. The progress of the reaction was followed by monitoring the disappearance of olefinic protons in the ${ }^{1} \mathrm{H}-\mathrm{NMR}$. After the reaction was complete, the contents of the tube were transferred (under nitrogen) to a $25 \mathrm{~mL}$ round bottom flask. Excess $\mathrm{HSiCl}_{3} \mathrm{was}$ evaporated and the product was isolated by kugelrohr distillation at $150{ }^{\circ} \mathrm{C}$ (pot temperature) and $0.03 \mathrm{~mm} \mathrm{Hg}$; white solid; yield $1.6 \mathrm{~g}, 47 \% .{ }^{1} \mathbf{H}-\mathbf{N M R} \delta(\mathrm{ppm}): 3.8(\mathrm{~s}, 3 \mathrm{H}), 2.3(\mathrm{t}, J=8,2 \mathrm{H}), 1.6(\mathrm{~m}, 4 \mathrm{H}), 1.2-1.5(\mathrm{~m}, 26 \mathrm{H}) .{ }^{13} \mathbf{C}-\mathbf{N M R} \delta(\mathrm{ppm}): 173.9$, 51.53, 34.39, 33.87, 29.60 (2C), 29.31, 29.19 (2C), 28.98, 29.17, 28.80 (2C), 28.73 (2C), 25.13, 24.52, 22.40.

\section{SAM Deposition}

SAMs were created using a $0.012 \mathrm{mM}$ solution of the ester-trichlorosilane in dicyclohexane, using the surface preparation procedures (cleaning and activation of the silicon wafers) and deposition conditions previously reported. ${ }^{45}$

\section{In situ surface transformation of ester- to carboxylic acid-functionalized monolayer}

Carboxylic acid monolayers were obtained by reaction with $\mathrm{AlI}_{3}$. This procedure was adapted from the reported procedure for converting methyl ester to carboxylic acid in solution. ${ }^{46}$ Ester-functionalized SAM coated wafers were placed in an oven dried $150 \mathrm{~mL}$ flat-bottom flask, containing a small magnetic stirring bar, equipped with a reflux condenser under a nitrogen atmosphere. Dry $\mathrm{CH}_{3} \mathrm{CN}(60 \mathrm{~mL})$ was added to the flask. After the solution had stirred for $15 \mathrm{~min}$ under nitrogen, $\mathrm{AlI}_{3}(0.6 \mathrm{~g}, 1.47$ mmol) was added. The reaction was heated at reflux $\left(85^{\circ} \mathrm{C}\right)$ for $2 \mathrm{~h}$ with extensive stirring. The reaction flask was cooled to room temperature and the substrate was removed, rinsed with fresh acetonitrile, and then with distilled water. It was placed in 
$10 \% \mathrm{HCl}$ for $1 \mathrm{~h}$ in order to remove aluminum salts. The wafer was then rinsed with water, dried with a stream of nitrogen, sonicated in ethanol $10 \mathrm{~min}$ and dried with a stream of nitrogen. The silicon wafer was analyzed by FTIR and showed the disappearance of the ester carbonyl peak and the presence of an acid carbonyl peak (Figure below).

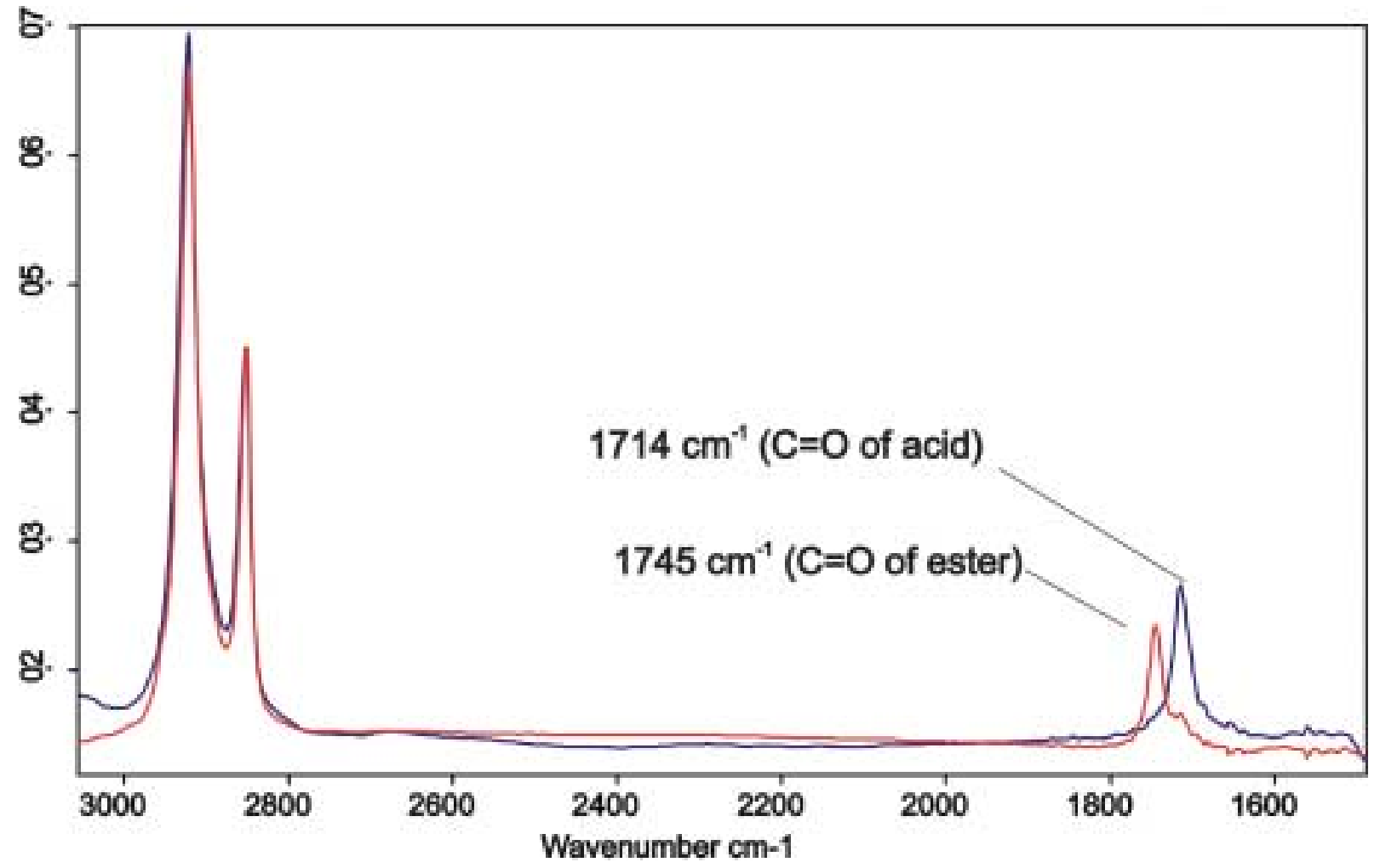

\section{SAM Characterization}

SAM surfaces (ester and acid) were characterized by their wetting properties (contact angle), XPS and thickness (ellipsometry).

\begin{tabular}{|c||c|c|c|}
\hline SAM & Adv / Rec Contact Angle & Carbonyl C in XPS, eV & Thickness, $\mathrm{nm}$ \\
\hline \hline Ester & $85 \pm 3 / 75 \pm 2$ & 289 & $2.26 \pm 0.20$ \\
\hline Acid & $58 \pm 5 / 45 \pm 3$ & 289 & $2.31 \pm 0.17$ \\
\hline
\end{tabular}

The procedures for each of these measurements was as follows:

Contact angle measurements (advancing and receding for water on the surface) were done using a Rame-Hart NRL goniometer. All samples were measured at least three times. To measure an advancing contact angle, a small drop (approximately $3 \mu \mathrm{L}$ ) of deionized, distilled water was placed on the surface, while the needle is in the drop. The contact angle was measured before the boundary of the drop moved. A similar procedure was used for the receding contact angle measurements. While the needle is in the drop, a fixed volume of water is withdrawn, and the reading is done before the boundary of the drop moves. The measurement was done at room temperature and in a controlled environment room with $45 \%$ relative humidity.

XPS (X-ray photoelectron spectroscopy) was done on a Perkin Elmer ESCA 5400 using an $\mathrm{Al} \mathrm{K}_{\alpha}$ source, at a base pressure of $10^{-9}$ Torr and a take-off angle of $90^{\circ}$. High-resolution multiplex spectra were collected on a $\sim 2-3 \mathrm{~mm}$ spot, using $40 \mathrm{eV}$ pass energy and a resolution of $50 \mathrm{eV}$. The spectrometer was calibrated according to standard procedures using $\mathrm{Au} 4 \mathrm{f}_{7 / 2}$ and $\mathrm{Cr} 2 \mathrm{p}_{3 / 2}$ peaks at $83.98 \mathrm{eV}$ and $932.67 \mathrm{eV}$, respectively. 
Film thickness was measured using a Model M44 ellipsometer (J.A Woollam Co.). The measurements were done using 44 wavelengths between $680-1108 \mathrm{~nm}$ and were analyzed using the instrument's (VASE) software. Measurements were made after calibration against a $25.0 \mathrm{~nm} \mathrm{SiO} 2$ layer on $\mathrm{Si}$. Data was collected at take-off angles of $68^{\circ}-70^{\circ}$.

\section{Equilibria calculations within the proposed model}

To support the model that the first $\mathrm{pK}$ involves deprotonation of only the monomeric $\mathrm{COOH}$, we consider the process of deprotonation of the carboxylic acid as occurring in parallel to the equilibration of the variously aggregated $\mathrm{COOH}$ species. Since we cannot separately characterize the chemistry of the dimers and oligomers, they are considered herein under the general heading of "aggregates".

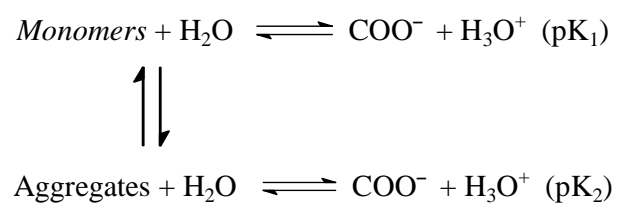

The amount of $\mathrm{COO}^{-}$species in solution at values of $\mathrm{pD}<7$, would be given by the equation:

$$
p D=p K_{a}+\log \frac{\left[\mathrm{COO}^{-}\right]}{[\text {monomer }]}
$$

if $\mathrm{pK}_{1}=4.9$, at $\mathrm{pD}=2.2 \quad[$ monomer $]=20 \%$ (from experimental data); the expected $\left[\mathrm{COO}^{-}\right]=0.04 \%$ (near zero)

at $\mathrm{pD}=6.1$ the expected $[$ monomer $]=4 \%$ (too small to measure); $\left[\mathrm{COO}^{-}\right]=50 \%$ (from experimental data).

\section{FTIR Spectra of the $2800-3000 \mathrm{~cm}^{-1}$ spectral region as a function of changes in $\mathrm{pD}$ of the solution}

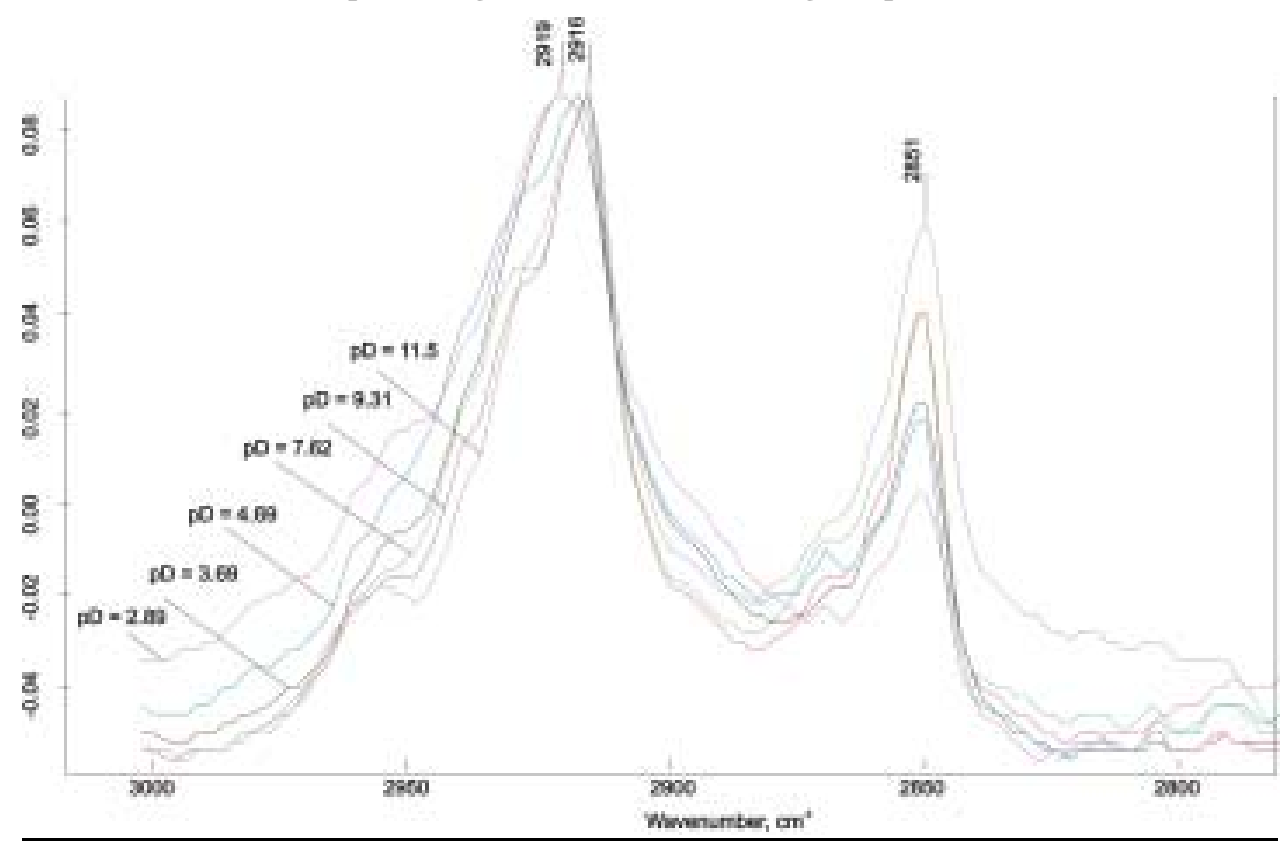

References

(43) Balachander, N.; Sukenik, C. N. Langmuir 1990, 6, 1621

(44) Vallant, T.; Kattner, J.; Brunner, H.; Mayer, U.; Hoffmann, H. Langmuir 1999, 15, 5339-5346.

(45) Collins, R. J.; Bae, I. T.; Scherson, D. A.; Sukenik, C. N. Langmuir 1996, 12, 5509-5511

(46) Mahajan, A. R.; Dutta, P. K.; Boruah, R. C.; Sandhu, J. S. Tetrahedron Letters 1990, 31, 3943-3944. 